\title{
Negative pressure ventilation in the treatment of acute respiratory failure: an old noninvasive technique reconsidered
}

\author{
A. Corrado, M. Gorini, G. Villella, E. De Paola
}

\begin{abstract}
Negative pressure ventilation in the treatment of acute respiratory failure: an old noninvasive technique reconsidered. A. Corrado, M. Gorini, G. Villella, E. De Paola. CERS Journals Ltd 1996.

ABSTRACT: Noninvasive mechanical ventilatory techniques include the use of negative and positive pressure ventilators. Negative pressure ventilators, such as the "iron lung", support ventilation by exposing the surface of the chest wall to subatmospheric pressure during inspiration; whereas, expiration occurs when the pressure around the chest wall increases and becomes atmospheric or greater than atmospheric.

In this review, after a description of the more advanced models of tank ventilators and the physiological effects of negative pressure ventilation (NPV), we summarize the recent application of this old technique in the treatment of acute respiratory failure (ARF). Several uncontrolled studies suggest that NPV may have a potential therapeutic role in the treatment of acute on chronic respiratory failure in patients with chronic obstructive pulmonary disease and restrictive thoracic disorders, reducing the need for endotracheal intubation. In the paediatric field, after substantial technical improvement, NPV has been successfully reintroduced for the treatment of ARF due to neonatal distress syndrome and bronchopulmonary dysplasia, and for the weaning from positive pressure ventilation in intubated patients.

The positive results of these reports need to be formally confirmed by further prospective and controlled studies before recommending the generalized use of negative pressure ventilation in acute respiratory failure as a standard of care.

Eur Respir J., 1996, 9, 1531-1544.
\end{abstract}

Unità di Terapia Intensiva Respiratoria, Villa d'Ognissanti, Azienda Ospedaliera di Careggi, Firenze, Italy.

Correspondence: A. Corrado

Unità di Terapia Intensiva Respiratoria

Villa d'Ognissanti

Viale Pieraccini, 24

50139 Firenze

Italy.

Keywords: Acute respiratory failure chronic obstructive pulmonary disease iron lung

negative pressure ventilation

neuromuscular disorders

paediatric diseases

Received: October 71995

Accepted after revision January 301996
Conventional mechanical ventilation via endotracheal intubation or tracheostomy is a life-saving procedure in the treatment of acute respiratory failure (ARF); however, it exposes patients to severe complications linked either to the tracheal tube or tracheostomy, or to mechanical ventilation itself [1-3].

To reduce the need for endotracheal intubation, noninvasive ventilatory techniques have recently been used to treat ARF. Even though benefits of noninvasive ventilation compared with intubation with an artificial airway in ARF have not been firmly established, the use of noninvasive ventilatory support has many advantages, including the possibility of avoiding sedative agents, facilitating communication between patients and care providers, and preserving functions, such as swallowing and coughing. Noninvasive mechanical ventilatory techniques include the use of negative and positive pressure ventilators. Negative pressure ventilators, such as the "iron lung", support ventilation by exposing the surface of the chest wall to subatmospheric pressure during inspiration; whereas, expiration occurs when the pressure around the chest wall increases and becomes atmospheric or greater than atmospheric. Positive pressure ventilators deliver pressure directly to the airway through a face or nasal mask. In this review, after a brief description of the historical development of negative pressure ventilation (NPV) and of the more advanced models of tank ventilators, we will focus on the clinical application of NPV in paediatric and adult medicine.

\section{Historical notes}

The use of a body-enclosing apparatus to produce ventilation is not a new idea. In 1832, DALziel [4] described a bellows-operated box with a seal around the neck or shoulders, which was said to have produced breathing movements in a "drowned seaman". In 1876 in Paris, WoILLEZ [5] built what was probably the first workable tank ventilator. This apparatus called "Spirophore" (fig. 1) was strikingly similar both in design and concept to the respirator introduced in 1931 by EMERSON [6] (fig. 2). The lack of electric power was a serious impediment and it was driven by hand-operated bellows. In 1889, DoE [8] described a box for resuscitating the newborn, developed by Braun in Vienna (fig. 3). In 1919 ChILLINGworth and HoPKINS [10] reported the development and utilization of a dog plethysmograph, in which an electric pump could produce ventilation by rhythmic variations in pressure.

The first tank ventilator (fig. 4) to be of clinical value was that developed at Harvard University Medical School 


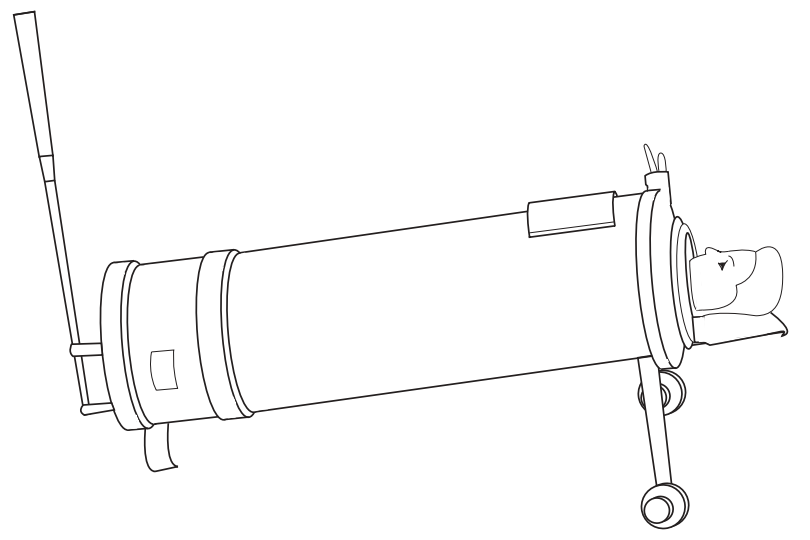

Fig. 1. - A schematic design of Woillez's Spirophore (1854). (Used with permission, from the Editor of The Lancet).

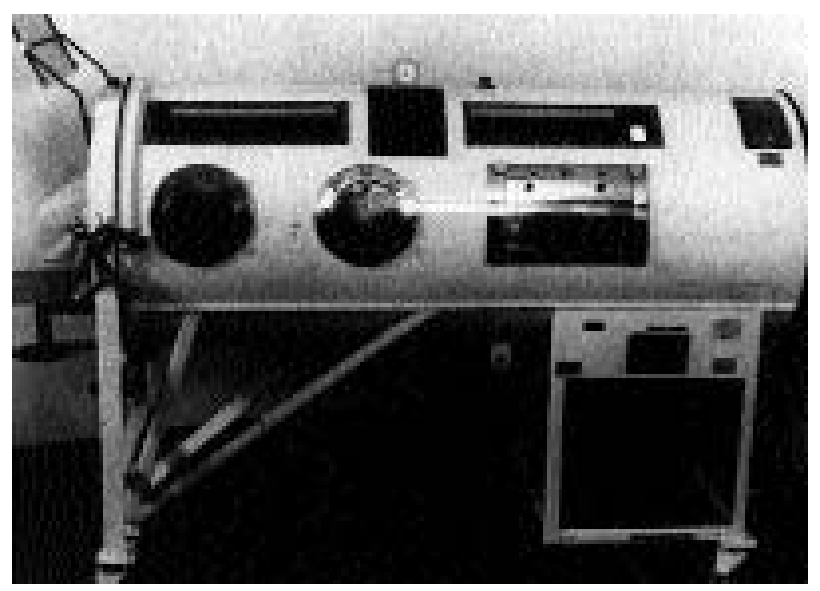

Fig. 2. - Emerson Iron Lung (1931). (Used with permission, from HiLL [7]).

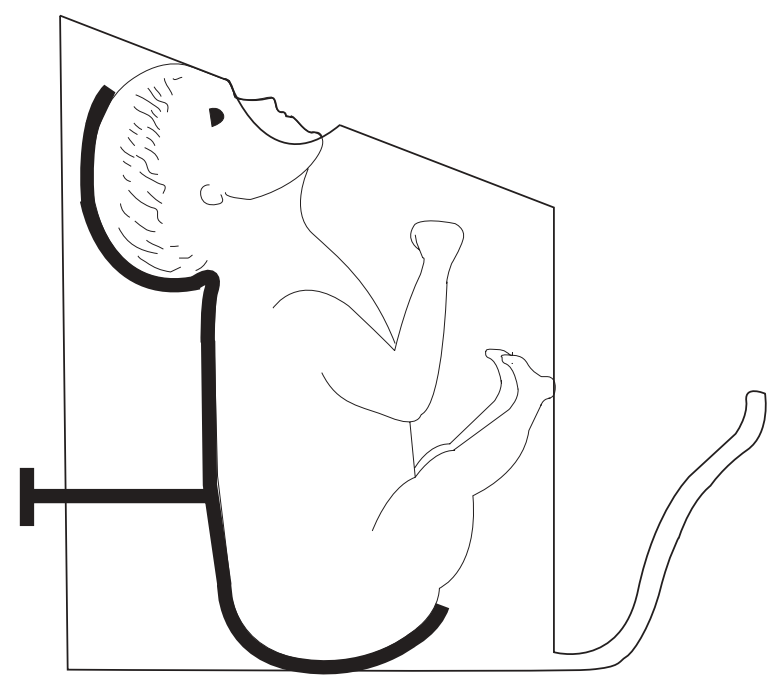

Fig. 3. - Egon's Braun resuscitation box for the newborn (1889). (Used with permission, from Woolam [9]).

by DRINKER and co-workers $[11,12]$ in 1928 . This ventilator was a sheet metal cylinder sealed at one end. The other end had a flat lid to which was attached a rubber collar. The patient's head and neck protruded through the collar and rested on a adjustable support attached to the

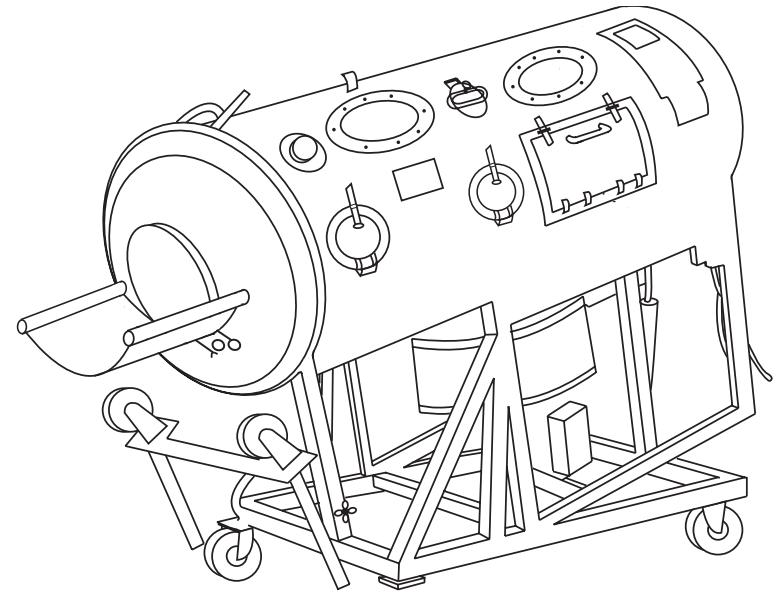

Fig. 4. - Drinker Collins respirator (1931). (Used with permission, from WoOLAM [9]).

outside of the tank. The sides of the cylinder had boattype portholes for observing the patient and small holes for introducing manometers, blood pressure cuffs and stethoscopes. The electric pump ran continuously, and positive and negative pressure was fed to the tanks via a system of valves. Drinker designed several modified versions of his tank ventilator, and these were widely and successfully used during the poliomyelitis epidemics of the next $30 \mathrm{yrs}$. "In the late 1950s there were at the Massachusetts General Hospital so many polio patients using iron lung that an entire floor had to be gutted" [12]. The effort to improve design and technology of tank ventilators was weakened by clinical evidence that positive pressure ventilation, using an endotracheal tube or a tracheostomy, was more successful in poliomyelitic patients [13]. In the 1950s and the 1960s there were major technological advances in the manufacturing of positive pressure ventilators, causing a marked decrease of the clinical application of NPV. A few investigators, however, have continued to manage acute and chronic respiratory failure by using negative pressure ventilators.

\section{Modern negative pressure ventilators}

Most of the modern tank ventilators (fig. 5) are constructed of aluminium and plastic, and are, therefore,

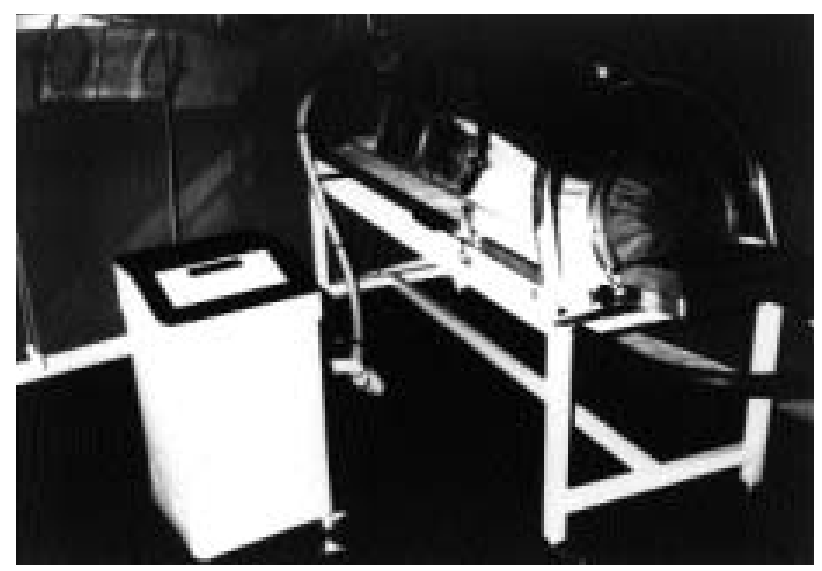

Fig. 5. - Dima Negavent "Portable Lung". 
lighter than the old models [14]. The patient's body rests on a thin mattress and the head protrudes through a porthole at one end of the ventilator. A head and neck rest is provided in most designs to ensure comfort and to prevent obstruction of the upper airway. Most tank ventilators have windows that permit patient observation and portholes through which catheters and monitor leads can be passed. Portholes also allow access to the patient for procedures, such as arterial blood gas sampling. In some models, the patient's head can be raised so that the aspiration of material from the pharynx into the trachea may be prevented.

Negative pressure is generated by bellow pumps incorporated into the structure of the ventilator or by separate rotary pumps. These pumps are pressure-cycled, i.e. the ventilator continues to develop subatmospheric pressure until a predetermined level is reached. Most tank ventilators have controls in order to set the pressure to be delivered during inspiration and expiration independently, and also inspiratory $\left(t_{\mathrm{I}}\right)$ and expiratory $\left(t_{\mathrm{E}}\right)$ times [15]. All negative pressure ventilators provide control mode; additionally, some provide assist and assist-control modes, whereby patient-generated negative pressure at the nares triggers the machine. Other devices utilize a thermistor at the nares to trigger a breath [16]. The data on the trigger sensitivity of negative pressure ventilators are very scarce [17]; this matter requires further studies.

At the present time, negative pressure ventilation can be delivered by four modes: 1) cyclical negative pressure; 2) negative/positive pressure; 3) continuous negative extrathoracic pressure (CNEP); and 4) negative pressure/CNEP.

\section{Cyclical negative pressure}

In this mode, the ventilator generates the preset subatmospheric pressure during inspiration, whereas expiration is passive.

\section{Negative/positive pressure}

This mode is a combination of negative pressure during inspiration with positive pressure during expiration. In patients with chest wall disorders, this combination has been found to increase tidal volume more than external negative pressure alone, and to reduce end-expiratory volume [18]. Some indirect evidence on how extrathoracic positive expiratory pressure works in obstructive diseases has been reported by CORMIER et al. [19], who studied the effects of the application of continuous positive extrathoracic pressure by iron lung in 11 asthmatic patients during acute induced bronchoconstriction. The authors reported that before and after methacholine challenge, which induced a moderate airway obstruction, functional residual capacity (FRC) decreased during the application of continuous positive extrathoracic pressure, reaching a plateau at $10 \mathrm{cmH}_{2} \mathrm{O}$ [19]. On a theoretical basis, it is unlikely that positive pressure provided by tank ventilators during expiration can increase expiratory flow in flowlimited chronic obstructive pulmonary disease (COPD) patients. However, FABBRI et al. [20] have recently studied the effects of the addition of external positive expiratory pressure during NPV provided by iron lung in 10 COPD patients with severe airflow obstruction and hypercapnia. The authors reported that external positive expiratory pressure increased $\mathrm{CO}_{2}$ concentration in expired air, whereas minute ventilation did not; this suggests that external positive pressure can result in an increase of alveolar ventilation in flow-limited COPD patients during ventilation with iron lung [20].

\section{Continuous negative pressure}

During this mode, a constant subatmospheric pressure is provided by the ventilator throughout the respiratory cycle and the patient breathes spontaneously. The physiological effects of CNEP have been found to be equivalent to those associated with positive end-expiratory pressure (PEEP) provided by positive pressure ventilators in experimental animals [21].

\section{Negative pressure/CNEP}

During this mode, the ventilator is set to superimpose inspiratory cycles of increased negative pressure on CNEP.

The characteristics of some models of negative pressure ventilators are reported in table 1 .

Table 1. - Characteristics of some iron lung models

\begin{tabular}{|c|c|c|c|c|c|c|c|c|c|c|}
\hline Model & $\begin{array}{l}\text { Inspiratory } \\
\text { pressure } \\
\mathrm{cmH}_{2} \mathrm{O}\end{array}$ & $\begin{array}{l}\text { Expiratory } \\
\text { pressure } \\
\mathrm{cmH}_{2} \mathrm{O}\end{array}$ & $\begin{array}{l}\text { CNEP* } \\
\mathrm{cmH}_{2} \mathrm{O}\end{array}$ & $\begin{array}{c}t \mathrm{I} \\
\mathrm{s}\end{array}$ & $\begin{array}{c}t \mathrm{E} \\
\mathrm{s}\end{array}$ & $\begin{array}{l}\text { End-inspiratory } \\
\text { expiratory } \\
\text { pauses }\end{array}$ & $\begin{array}{l}\text { Ventilation } \\
\text { modes }\end{array}$ & Trigger & $\begin{array}{l}\text { Head-up } \\
\text { tilting }\end{array}$ & Alarms \\
\hline $\begin{array}{l}\text { Emerson } \\
\text { Iron Lung }\end{array}$ & Up to -60 & - & - & $\ddagger$ & $\ddagger$ & - & $\mathrm{C}$ & No & No & No \\
\hline $\begin{array}{l}\text { Coppa } \\
\text { CA } 1001 \\
\text { Emerson }\end{array}$ & 0 to -80 & 0 to +80 & 0 to -20 & $0.4-6$ & $0.4-6$ & $0.3-1.9$ & $\mathrm{C}, \mathrm{A}-\mathrm{C}$ & Thermistor & $0-5^{\circ}$ & $\begin{array}{l}P \max \\
\mathrm{MF}\end{array}$ \\
\hline $\begin{array}{l}\text { 33-CR } \\
\text { Porta-lung } \\
\text { Lifecare }\end{array}$ & Up to -90 & - & Yes & Up to 5 & \# & - & $\mathrm{C}, \mathrm{A} / \mathrm{C}, \mathrm{A}$ & Pressure & No & No \\
\hline $\begin{array}{l}\text { NEV-100 } \\
\text { Porta-lung } \\
\text { Dima }\end{array}$ & -5 to -100 & -30 to +30 & -5 to -30 & $0.5-5$ & $\S$ & - & $\begin{array}{c}\mathrm{C}, \mathrm{A} / \mathrm{C}, \mathrm{C}+\mathrm{S} \\
\mathrm{A} / \mathrm{C}+\mathrm{S}\end{array}$ & Pressure & No & $\begin{array}{l}P \min \\
\mathrm{MF}\end{array}$ \\
\hline $\begin{array}{l}\text { Negavent } \\
\text { Plus }\end{array}$ & -8 to -80 & 0 to +80 & -8 to -80 & $*$ & $*$ & $0-30 \%$ & $\mathrm{C}, \mathrm{A}-\mathrm{C}$ & Pressure & No & $\begin{array}{l}P_{\max } \\
P_{\min }\end{array}$ \\
\hline
\end{tabular}

\$: rate about $10-30$ cycles $\mathrm{min}^{-1}$ in adult unit, I/E ratio 1/1; \#: rate $0-49$ cycles $\cdot \mathrm{min}^{-1}$, I/E ratio $1 / 3$ to inverse ratio; $\S$ : rate 4-60 cycles. $\min ^{-1}$, I/E ratio $1 / 0.5$ to $1 / 29.1$; *: rate $5-50$ cycles $\cdot \min ^{-1}$, I/E ratio $1 / 99$ to $5 / 1$. CNEP: continuous negative extrathoracic pressure; $t$ I: inspiratory time; $t \mathrm{E}$ : expiratory time; I/E: inspiratory/expiratory. C: control; A/C: Assist/Control; C+S: Control + Sigh; A/C+S: Assist/Control + Sigh; $P$ max: maximum pressure; $P$ min: minimum pressure; MF: machine failure. 


\section{Physiological effects of NPV}

\section{Gas exchange}

Tank ventilators are capable of maintaining normal arterial blood gas tensions even in patients with little or no spontaneous respiratory effort [14]. During mechanical ventilation with iron lung and airtight jacket, tidal volume and minute ventilation have been found to be related to the peak of the inspiratory negative pressure $[22,23]$. Recently, it has been reported in an experimental model that tidal volume during NPV is related both to the peak of negative pressure and the pressure waveform generated by the ventilator pump [24]; for the same peak of negative pressure a square wave produced a greater tidal volume than a half sine wave.

\section{Respiratory muscles}

The effects of NPV on respiratory muscle strength of COPD patients in ARF have been reported in only two studies [25, 26]. In these studies, an iron lung [25] and a ponchowrap [26] were used, respectively, to administer NPV. In these reports, NPV, carried out continuously for $6 \mathrm{~h}$ [26], or intermittently for 7 days $\left(8 \mathrm{~h} \cdot \mathrm{day}^{-1}\right)$ [25], was found to be effective in improving respiratory muscle strength and in decreasing arterial carbon dioxide tension $\left(P \mathrm{a}, \mathrm{CO}_{2}\right)$. The effects of NPV on electromyographic activity (EMG) of respiratory muscles in patients with ARF have not been investigated. Several studies, however, have reported that EMG of the respiratory muscles is reduced during NPV in patients with chronic respiratory failure due both to COPD and neuromuscular and skeletal disorders [27-30]. RoDENSTEIN and co-workers $[31,32]$ have studied the adaptation of normal subjects [31] and stable COPD patients [32] to mechanical ventilation by using a "Drinker tank respirator". The respirator was used in control mode with a respiratory frequency of 15-20 cycles. $\mathrm{min}^{-1}$; however, no data were provided regarding the set of inspiratory/expiratory time ratio. Not surprisingly, the EMG activity of the diaphragm was reduced only after familiarization with the ventilator [31, 32]. More recently, Gigliotti and co-workers [33, 34] studied the effects of NPV on EMG activity of the diaphragm and parasternal muscles in normal subjects [33] and in COPD patients [34]. In these studies, in which respiratory frequency, $t \mathrm{I}$, and $t \mathrm{E}$ were adjusted to approximate the subject's spontaneous timing components, NPV resulted in a substantial suppression of EMG activity of the inspiratory muscles [33-34]. In COPD patients, EMG activity of the diaphragm and parasternal muscles was reduced by 70 and $67 \%$, respectively, during NPV in comparison to spontaneous breathing [33, 34].

Although, in patients with acute respiratory failure, NPV acts by sustaining ventilation and by reducing their efforts to breathe, the mechanism for sustained improvement of gas exchange in patients receiving NPV intermittently is not so clear. Several mechanisms have been proposed, including respiratory muscle rest [34-37], improvement in the physiological dead space/tidal volume $\left(V_{\mathrm{D}} / V_{\mathrm{T}}\right)$ ratio [30], and reset of respiratory centre sensitivity to $\mathrm{CO}_{2}$ [30]. These hypotheses are not mutually exclusive and all could contribute to different degrees depending on the patient.

\section{Upper airway}

It has been reported that the application of NPV during sleep in normal subjects [38] and in patients with chronic respiratory failure due both to COPD [39] and neuromuscular disorders $[40,41]$ may result in the development of recurrent episodes of apnoea and hypopnoea, as well as altered sleep quality. In two controlled studies in normal subjects [38] and COPD patients [39], however, most obstructive events during NPV were associated with mild oxygen desaturation $(<3 \%)$, and only one subject had marked desaturations [39]. Furthermore, a recent controlled study in a small number of patients with neuromuscular disorders has shown that night-time NPV resulted in a general improvement of sleep quality and oxygen saturation [42]. SANNA et al. [43] have recently studied the site of upper airway obstruction during NPV. They found that, in normal subjects during voluntary respiratory muscle relaxation, NPV caused a decrease in the calibre of the upper airway at the glottic or supraglottic level [43].

The mechanisms of the upper airway obstruction observed with NPV have not been determined. During spontaneous breathing, the activation of pharyngeal and laryngeal muscles precedes the activation of inspiratory muscles, resulting in stiffening of the upper airway walls. When NPV is applied during sleep or in completely relaxed subjects, this co-ordinated respiratory muscle activity may be abolished; as a consequence the subatmospheric pressure developed in the upper airway during inspiration may result in collapse of the upper airway $[15,38,39,43]$. Recently, upper airway obstruction has been reported in two out of 10 patients with acute on chronic respiratory failure during treatment with NPV [44].

\section{Lower oesophageal sphincter (LOS)}

It has been reported that NPV may induce a LOS dysfunction in healthy subjects [45] and in COPD patients [46]. This dysfunction may cause regurgitation of stomach contents and, sometimes, their aspiration. However it has been shown that LOS dysfunction induced by NPV can be completely prevented by metoclopramide [46]. The administration of this drug should be considered when starting a patient on NPV, especially if any symptoms of gastro-oesophageal reflux occur [46].

\section{Cardiovascular effects}

Although the haemodynamic effects of NPV have not been extensively studied $[47,48]$, most clinicians believe that these effects are opposite to those of positive pressure ventilation (PPV), i.e. more physiological and more likely to maintain a normal cardiac output. As pointed out by Maloney and WhitTenberger [48], however, the exposure of the entire body (except for the airway opening) to NPV would result in the same adverse haemodynamic effects as occurs with PPV. This is because intrathoracic pressure is actually raised relative to body surface pressure, thereby reducing the gradient for venous 
return. SKabuRsis et al. [49] and LocKhat et al. [50] have shown that this is not the case when the application of NPV is confined to the thorax and upper abdomen by using cuirass or ponchowrap. Unlike tank ventilator, these machines selectively decrease intrathoracic pressure, so that right atrial pressure becomes more negative (relative to the rest of body), potentially enhancing the gradient for the venous return. SKABURSIS et al. [49] compared the effects of NPV plus negative end-expiratory pressure (NEEP) with PPV plus PEEP in six anaesthetized dogs with oleic acid induced pulmonary oedema. The two ventilatory modes were carefully matched for inspired oxygen fraction $\left(F \mathrm{I}, \mathrm{O}_{2}\right)$, breathing frequency, tidal volume, and the increase in FRC. Whereas gas exchange did not differ significantly between the two modes, cardiac output was higher during NPV plus NEEP than during PPV plus PEEP [49]. LOCKHAT et al. [50] compared the effects of PPV plus PEEP, NPV plus NEEP applied by iron lung, and NPV plus NEEP applied only to the thorax and upper abdomen by a grid and wrap device in seven anaesthetized dogs. The ventilatory variables were carefully matched during the three modes of ventilation. In agreement with the suggestions of MALONEY and WhITTENBERGER [48], the cardiac output with NPV plus NEEP applied by iron lung was similar to that with PPV plus PEEP, and it was greater with NPV plus NEEP applied by grid and wrap compared to the other two modes of ventilation [50]. More recently, AMBRosino et al. [51] have reported that the application of NPV by ponchowrap does not modify the cardiac output in stable COPD patients.

In conclusion, at the present time, few studies investigating the physiological effects of NPV in patients with ARF have been carried out. In particular, studies aimed at evaluating: 1) the real incidence of upper airway obstruction during NPV; and 2) the potential usefulness of assisted-controlled NPV in reducing this phenomenon would be useful. Further studies are needed to elucidate the effects of NPV on gas exchange and the cardiovascular system in patients with ARF.

\section{Clinical applications of NPV in acute respiratory failure}

\section{Paediatric diseases}

The management of respiratory failure in infancy and childhood traditionally includes the administration of additional inspired oxygen and the use of positive pressure ventilation via endotracheal intubation. This can result, especially in neonates, in significant complications, such as tube placement problems, increased risk of lower respiratory tract infection [52], long-term sequelae and problems of tracheostomies [15], barotrauma [53], and adverse haemodynamic effects $[47,54]$. In addition, the use of PPV may contribute to development of chronic lung disease, particularly in preterm infants [55]. In the 1970s, several uncontrolled [56-58] and controlled [59, 60] studies showed that NPV was effective in the management of the neonatal respiratory distress syndrome. However, the application of this technique was limited by technical problems such as upper airway obstruction, sores from the neck seal, difficulties in achieving access to the patients and maintaining a neutral thermal environment for newborn infants [60]. Furthermore, it was suggested that the collar could induce a garrotting effect responsible for the potentially harmful increase in endocranial pressure [61]. More recently, however, after substantial technical improvement [62], NPV has been reintroduced for the treatment of respiratory failure [63, 64]. PALMER et al. [65], using a new model of tank ventilator (fig. 6), which incorporates a newly developed latex neck seal designed to avoid compression, have reported no significant jugular venous occlusion linked to the neck seal.

SAMUELS and Southall [62] studied, in an uncontrolled clinical trial, the effects of NPV in 88 infants and young children (aged 1 day to 2 yrs) with respiratory failure principally due to bronchopulmonary dysplasia and neonatal distress syndrome. When NPV was initiated, 59

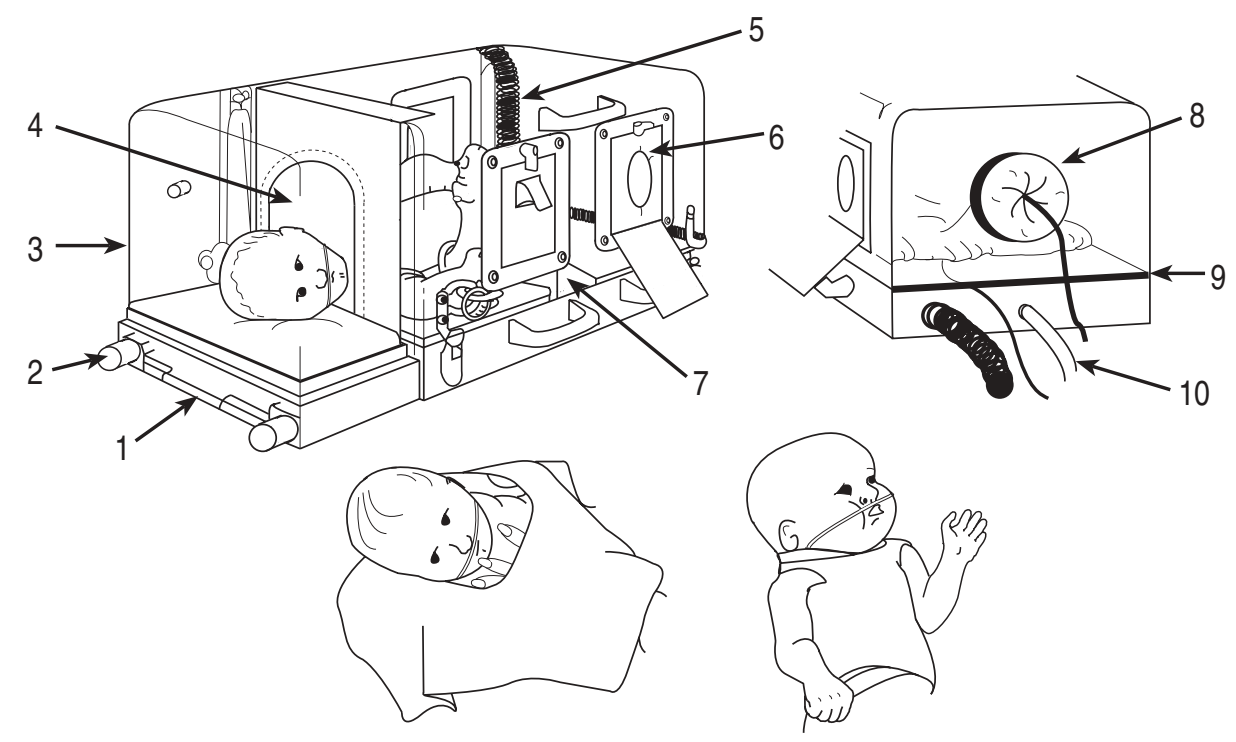

Fig. 6. - Negative pressure ventilator for infants. 1) Details of the chamber include release for head section; 2) rods on which it slides out away from chamber base; 3) head box; 4) latex neck seal taped up over arch lid; 5) gas strut hinges; 6) foam gasket in porthole; 7) footplate to support infant when chamber is tilted up; 8) porthole for infusions, etc; 9) rubber strip below which monitoring leads, etc. can enter chamber; 10) tubing to pressure monitor. (Modified and used with permission, from SAmuels and Southall [62]). 
patients were receiving an $\mathrm{F}_{\mathrm{I}} \mathrm{O}_{2}$ equal or more than $50 \%$, whereas 40 patients were ventilated with PPV. After $2 \mathrm{~h}$ of ventilatory treatment carried out with NPV, 75 patients $(85 \%)$ needed a lower $F_{\mathrm{I}}, \mathrm{O}_{2}$ and a further decrease in $F_{\mathrm{I}, \mathrm{O}_{2}}$ was achieved in 74 patients after $48 \mathrm{~h}$. Of 40 patients intubated at the start of treatment, 28 were successfully extubated with the aid of negative extrathoracic pressure and 24 survived. Fifty four patients $(61 \%)$ survived and were discharged; among these, six needed to be ventilated at home with a negative extra thoracic ventilatory support. No potential complications, such as fluid retention, intrathoracic air leak, gastro-oesophageal reflux with aspiration and neck soreness were reported. Upper airway obstruction due to subglottic stenosis after extubation became evident during NPV in only one infant, and required tracheostomy [62]. These results would suggest that the new negative extrathoracic pressure ventilator employed by SAMUELS and Southall [62] could be considered a safe and effective respiratory support in the management of ARF in infants and young children. The lack of a control group, however, weakened the conclusion of this interesting report.

Paediatric patients undergoing cardiac surgery for congenital heart disease are exposed to the risk of phrenic nerve palsy, that can cause respiratory failure necessitating prolonged mechanical ventilation via an endotracheal tube or a tracheostomy. Diaphragmatic plication is usually performed in the treatment of phrenic nerve palsy after the failure of conservative methods, and when the patient cannot be weaned from positive airway pressure ventilation or has a persistent oxygen requirement [66]. A recent uncontrolled study reported that NPV can facilitate the weaning from PPV via endotracheal tube, and reduce the need of diaphragmatic plication in patients with respiratory failure following phrenic nerve palsy after cardiac surgery [67].

Another recent application of NPV has been reported by HARTMANN et al. [68] in the treatment of central hypoventilation syndrome. This noninvasive ventilatory technique allowed seven of nine intubated patients $(78 \%)$ to be weaned from PPV. Three patients needed nasal continuous positive airway pressure (CPAP) in association with NPV for upper airway obstruction after extubation, two of them for a short period ( 2 weeks and 7 days, respectively) and one permanently. All patients were discharged and continued to be treated with ventilatory support at home. Two of the seven patients treated with NPV became successively free from ventilator [68].

Infants with ARF who fail to respond to conventional ventilation are considered elective candidates for extracorporeal membrane oxygenation (ECMO). This technique, though it can be life-saving, is associated with significant complications [69] and high mortality rate [70]. A recent uncontrolled study, reported that the use of CNEP administered by a tank ventilator in conjunction with intermittent mandatory ventilation via endotracheal tube was successful in five newborn suffering from respiratory failure and persistent pulmonary hypertension, thus avoiding the use of ECMO [63]. All patients in this study were initially treated with intermittent mandatory ventilation incorporating PEEP, and were switched successively from PEEP to CNEP when the former ventilatory method and an of $F_{\mathrm{I}, \mathrm{O}_{2}}$ of $100 \%$ failed to correct hypoxaemia
[63]. The benefit of combining intermittent mandatory ventilation and CNEP in these patients has recently been confirmed by the same group in a prospective randomized study [71]. In this study, 30 consecutive neonates with severe hypoxaemia (arterial oxygen tension $\mathrm{Pa}_{\mathrm{a}} \mathrm{O}_{2}$ $4.8 \pm 1.1 \mathrm{kPa}(36 \pm 8 \mathrm{mmHg}))$ all receiving conventional PPV were randomly assigned to two different modes of ventilation: intermittent mandatory ventilation incorporating PEEP or intermittent mandatory ventilation combined with CNEP. The randomization occurred if conventional positive pressure ventilation failed to increase $P \mathrm{a}, \mathrm{O}_{2}$ level higher than $6.0 \mathrm{kPa}(45 \mathrm{mmHg})$ while the patients were receiving $100 \%$ oxygen. Among the 30 infants, 23 fulfilled criteria for treatment with ECMO. Patients crossed over to the other mode of ventilation if the $\mathrm{Pa}, \mathrm{O}_{2}$ remained $<6.0 \mathrm{kPa}(<45 \mathrm{mmHg})$ after at least $2 \mathrm{~h}$ of randomized therapy. A statistically significant difference was ascertained in the number of patients who crossed over from PEEP to CNEP (73\%) in comparison with those who crossed over from CNEP to PEEP (13\%). In the ECMOqualifier subset of patients, nine $(82 \%)$ crossed over from PEEP to CNEP, and only one $(8 \%)$ crossed over from CNEP to PEEP. Thirty minutes after randomization, patients treated with CNEP showed a marked rise in $\mathrm{Pa}, \mathrm{O}_{2}$ values $9.2 \pm 2.3 \mathrm{kPa}(69 \pm 17 \mathrm{mmHg})$, which were statistically different in comparison with those observed in patients treated with PEEP $\left(\mathrm{Pa}_{\mathrm{a}} \mathrm{O}_{2}, 6.4 \pm 3.6 \mathrm{kPa}(48 \pm 27\right.$ $\mathrm{mmHg}) ; \mathrm{p}<0.05)$. The use of CNEP did not increase morbidity and the overall survival rate was $83 \%$ [71]. These data suggest that CNEP is a noninvasive and safe method for rescue of infants with severe hypoxaemia, and can be successfully employed in association with intermittent mandatory ventilation as initial therapy for infants who meet ECMO criteria.

At the present time, some uncontrolled studies suggest a potential therapeutic role for NPV in the treatment of ARF due to neonatal distress syndrome and bronchopulmonary dysplasia, and in the weaning from PPV in intubated patients. These points need to be confirmed by prospective and controlled studies. The employment of CNEP in association with intermittent mandatory ventilation in intubated patients has been found to be more efficacious than PEEP in patients who meet ECMO criteria. However, further studies confirming these results are needed before adopting this ventilatory modality as general practice in the clinical application of patients who meet ECMO criteria.

\section{$A R F$ in COPD with chronic respiratory insufficiency}

Anecdotal cases concerning the successful application of iron lung in the treatment of ARF due to acute exacerbations of COPD were reported in the 1950s. BOUTOURLINEYoung and WhitTENBERGER [72] described two cases of pulmonary emphysema with hypercapnia and hypoxaemia treated in a body respirator; one patient died and the other survived and was able to return to his former occupation. STONE et al. [73] successfully treated by iron lung three patients with chronic pulmonary disease during ARF. LOVEJoY et al. [74] reported that, in two out of three patients with severe COPD in comatose state and with severe hypercapnia and respiratory acidosis, the use 
of iron lung resulted in recovery. One of the two successful cases improved dramatically during mechanical ventilation after the positioning of an oropharyngeal airway [74]. In five out of seven severe COPD patients with respiratory acidosis, NPV, delivered in assist mode by a cuirass, increased alveolar ventilation with a mean decrease of $P \mathrm{a}, \mathrm{CO}_{2}$ of $5.3 \mathrm{kPa}(39.6 \mathrm{mmHg})$ [75]. In two of the three patients who died, the cause of death was related to extra respiratory complications [75].

In the 1960s, there were major technological advances in the manufacturing of positive pressure ventilators. Subsequently, COPD patients in ARF were generally managed with positive pressure ventilators by endotracheal methods. However, NPV has continued to be used in Europe and especially in Italy, as reported by uncontrolled studies [76, 77].

Even though mechanical ventilation via endotracheal intubation is considered the standard ventilatory treatment in COPD patients with ARF, numerous complications of this technique have been recognized [2]. For this reason, there is no wide consensus as to the best moment to start mechanical ventilation in patients with acute on chronic respiratory failure. PetTy et al. [78] and CuRTIS and Hudson [79] suggest that COPD patients with acute respiratory failure (ARF) who fail to show improvement with conservative management (controlled low-flow oxygen, skilful pharmacological intervention and intensive nursing) should be given ventilatory support. When endotracheal intubation and mechanical ventilation is mandatory, it is essential to reduce to a minimum the length of treatment, as negative prognostic implications and infective complications may occur from long-term application [80]. An increased mortality rate from the first (42\%) to the seventh day $(75 \%)$ of treatment has been reported in COPD patients undergoing mechanical ventilation [81]. Furthermore, the percentage of pulmonary infections in patients mechanically-ventilated was found to increase in proportion to the days of treatment [82]. WESSEL-AAS et al. [83], in a series of patients with chronic respiratory insufficiency in ARF, $32 \%$ of whom were COPD patients, reported more complications in subjects who underwent positive pressure ventilation after intubation than in those treated with a body ventilator. From these considerations, many attempts have recently been made to deliver partial or total ventilatory support in noninvasive manner in COPD patients with acute on chronic respiratory failure.

Negative pressure ventilation has been tested in several uncontrolled studies as listed in table 2. Tank ventilators $[25,84,85]$ and ponchowrap $[26,86]$ have been used to deliver NPV in COPD patients with ARF (table 2 ). In all these studies, NPV was provided in control mode. In 560 patients (475 of whom had COPD) with chronic respiratory insufficiency, iron lung was applied successfully during an episode of ARF [84]. NPV in association with medical treatment determined a significant improvement of gas exchanges and $\mathrm{pH}$. A mortality rate of $10.5 \%$ was reported in COPD patients. In this study, however, no indications were reported on the patients' level of consciousness on admission and on the duration of ventilatory treatment. Particularly interesting is the fact that the mortality rate of COPD patients in this study [84] is similar to that reported in a recent study of ours [87] aimed at analysing retrospectively the results obtained in 16 yrs of activity in our respiratory intensive care unit (ICU). In this period (1975-1991) we treated 2,564 patients $(2,011$ with COPD and 553 with restrictive thoracic disorders) by use of NPV for ARF. The mortality rate during hospitalization was $9.9 \%$ for the patients as a whole, and 10 and $8.9 \%$ for patients with COPD and restrictive thoracic disorders, respectively. The length of stay in the respiratory care unit was $10.5 \pm 9.5$ days [87]. In 1990, we reported [25] the effects of NPV in nine COPD patients in ARF without signs of deteriorating sensorium (stage 1 WEITZENBLUM [88] classification), who underwent ventilatory treatment for $8 \mathrm{~h} \cdot \mathrm{day}^{-1}$ for 7 days. The ventilatory treatment resulted in a significant improvement in $\mathrm{Pa}_{\mathrm{a}} \mathrm{O}_{2}, \mathrm{~Pa}_{\mathrm{a}} \mathrm{CO}_{2}$ and $\mathrm{pH}$ (table 2). No complications related to NPV were reported [25].

MonTSERRAT et al. [26] evaluated the acute effects of NPV in 20 consecutive patients with COPD in ARF due to bronchial infection (table 2). Arterial blood gas tensions and maximal inspiratory pressure (MIP) were measured before and after $6 \mathrm{~h}$ of NPV or conventional medical treatment given in random order on two consecutive day. The authors reported that NPV increased MIP and decreased $P \mathrm{a}, \mathrm{CO}_{2}$ whereas $P \mathrm{a}, \mathrm{O}_{2}$ remained unchanged. No change in these parameters was observed with conventional medical treatment. Although all patients completed the study, six were not compliant with the ventilatory treatment. This subset of patients did not show improvement in MIP and $P$ a, $\mathrm{CO}_{2}$ [26]. SAURET et al. [86] studied 17 patients with severe COPD (forced expiratory volume in one second (FEV1) $0.60 \pm 0.15 \mathrm{~L}$ ) in acute hypercapnic respiratory failure due to intercurrent bronchial infection. All patients underwent NPV, for $6 \mathrm{~h}$ on one day only, in association with oxygen therapy. Oxygen was administered using Venturi mask with inspired $\mathrm{O}_{2}$ concentrations of $24 \%$ at the beginning of treatment, $28 \%$ during the first hour,

Table 2. - Studies on the use of negative pressure ventilation in COPD patients with acute respiratory failure

\begin{tabular}{|c|c|c|c|c|c|c|c|c|c|c|c|c|}
\hline \multirow{2}{*}{$\begin{array}{l}\text { First } \\
\text { author }\end{array}$} & \multirow[t]{2}{*}{ [Ref] } & \multirow{2}{*}{$\begin{array}{c}\text { Type of } \\
\text { ventilator }\end{array}$} & \multirow{2}{*}{$\begin{array}{c}\text { Pts } \\
\mathrm{n}\end{array}$} & \multicolumn{3}{|c|}{ Baseline } & \multicolumn{3}{|c|}{ After NPV } & \multirow{2}{*}{$\begin{array}{c}\text { Duration } \\
\text { of NPV } \\
h\end{array}$} & \multirow{2}{*}{$\begin{array}{c}\text { Hospital } \\
\text { stay } \\
\text { days }\end{array}$} & \multirow{2}{*}{ Control } \\
\hline & & & & $\begin{array}{l}\mathrm{Pa}_{\mathrm{a}, \mathrm{O}_{2}} \\
\mathrm{kPa}\end{array}$ & $\begin{array}{c}{\mathrm{Pa}, \mathrm{CO}_{2}}_{\mathrm{kPa}} \\
.\end{array}$ & $\mathrm{pH}$ & $\begin{array}{c}\mathrm{Pa}_{\mathrm{a}, \mathrm{O}_{2}} \\
\mathrm{kPa}\end{array}$ & $\begin{array}{c}P \mathrm{a}, \mathrm{CO}_{2} \\
\mathrm{kPa}\end{array}$ & $\mathrm{pH}$ & & & \\
\hline GunELLA & [84] & Iron lung & $560 *$ & 5.6 & 11.6 & 7.22 & 9.3 & 6.4 & 7.37 & NR & 21 & None \\
\hline CORRADO & [25] & Iron lung & 9 & 5.7 & 9.0 & 7.33 & 8.2 & 7.0 & 7.37 & 56 & NR & 7 stable \\
\hline MONTSERRAT & г [26] & Ponchowrap & 20 & 6.4 & 8.1 & 7.32 & 6.4 & 6.8 & 7.38 & 6 & NR & $6 \mathrm{~h}$ rest \\
\hline SAURET & [86] & Ponchowrap & 17 & 6.3 & 9.8 & 7.34 & 7.0 & 8.6 & 7.39 & 6 & NR & None \\
\hline CORRADO & [85] & Iron lung & 93 & 4.7 & 11.3 & 7.25 & 8.1 & 6.4 & 7.38 & NR & 12 & None \\
\hline
\end{tabular}

*: $\mathrm{COPD}=475$. COPD: chronic obstructive pulmonary disease; [Ref]: reference number; Pts: patients; $P_{\mathrm{a}, \mathrm{O}_{2}}$ : arterial oxygen tension; $\mathrm{Pa}, \mathrm{CO}_{2}$ : arterial carbon dioxide tension; NPV: negative pressure ventilation; NR: not reported. 
and thereafter $30 \%$ until the $6 \mathrm{~h}$ period of NPV was completed. A significant improvement of arterial blood gas values and $\mathrm{pH}$ was ascertained during ventilatory treatment. One hour after the end of ventilatory treatment, the same $F \mathrm{I}_{1} \mathrm{O}_{2}$ of $24 \%$ during spontaneous breathing produced a better degree of oxygenation in comparison to that observed in basal condition $\left(\mathrm{P}_{\mathrm{a}}, \mathrm{O}_{2} 7.1 \pm 0.8\right.$ versus $6.3 \pm 0.4 \mathrm{kPa}(53.3 \pm 6$ versus $47.2 \pm 3 \mathrm{mmHg}))$, whereas the improvement in $\mathrm{Pa}_{\mathrm{a}} \mathrm{CO}_{2}$ and $\mathrm{pH}$ obtained during NPV remained unchanged. All patients reported a marked improvement in their dyspnoea, all were compliant with the ventilator, and none of them experienced musculoskeletal pain or other complications. The authors concluded that NPV permits increased oxygen flow in patients with severe hypercapnic respiratory failure due to advanced COPD, and prevents the need, in some cases, of more aggressive ventilatory support [86].

NPV used as a first-line of treatment in severe COPD patients with ARF was found to be associated with a good outcome and long-term prognosis [85]. In this uncontrolled report, 105 COPD patients with chronic respiratory insufficiency admitted to our respiratory intensive care unit from 1976 to 1980 for ARF were retrospectively evaluated. All subjects underwent NPV by means of iron lung to overcome the acute episode. ARF was defined as a condition of acute exacerbation of the chronic disease, which was characterized by increase of dyspnoea at rest, signs of right heart failure (ankle oedema), severe hypoxaemia $\mathrm{Pa}, \mathrm{O}_{2}<6.7 \mathrm{kPa}(<50 \mathrm{mmHg})$, hypercapnia $P$ a, $\mathrm{CO}_{2}>6.7 \mathrm{kPa}(>50 \mathrm{mmHg})$, and $\mathrm{pH}<7.30$. This condition could be associated with loss of consciousness or deteriorated sensorium. Of the 105 patients included in the study, 62 were in coma [89] on admission and 43 showed neurological signs of deteriorating sensorium. The main causes leading to ARF were: exacerbations of chronic disease $(\mathrm{n}=58 ; 55 \%)$ and bronchopneumonia $(n=42 ; 40 \%)$. Twelve patients died during hospitalization, whilst 93 were successfully weaned and were included in a follow-up lasting $5 \mathrm{yrs}$. Six patients were lost after discharge. All relapses of ARF during follow-up were treated by NPV. The survival rates after 1 and 5 yrs were 82 and $37 \%$, respectively [85]. The survival observed in our patients was better than that reported previously in COPD patients with ARF submitted to conventional mechanical ventilation [90]. Although all comparisons with previous studies can be subjected to a number of biases (differences in the selection of patients, medical therapy and degree of monitoring applied), these data suggest that the treatment of acute respiratory failure in COPD patients by NPV could improve survival. In a subsequent study, aimed at investigating the effects of NPV, in overcoming acute episodes and relapses of ARF, combined with long-term oxygen therapy, we confirmed a good long-term survival in COPD patients treated with NPV [91].

NPV provided by iron lung has recently been used by Del Bufalo et al. [92] to facilitate the weaning from mechanical ventilation via endotracheal intubation in COPD patients. Nineteen patients with COPD (10 cases) or restrictive thoracic disorders (9 cases) who failed to be weaned with conventional methods (T-piece, pressure support ventilation, CPAP and synchronized intermittent mandatory ventilation) were submitted to weaning trial with iron lung. After adaptation to ventilation with iron lung, patients were extubated during NPV. Each subject was carefully monitored and, if gas exchange and haemodynamic status remained stable, ventilation was discontinued. Successively, NPV was provided intermittently and then slowly tapered off as the patient's clinical condition improved. With this method, 17 (eight with COPD) of the 19 patients were successfully weaned and discharged from the ICU [92]. Controlled studies are needed to confirm these interesting results and to compare this method with the conventional weaning techniques.

The majority of studies reporting successful employment of NPV for the treatment of COPD patients with ARF are retrospective and uncontrolled. Even though these studies involved a large number of patients and were performed by physicians experienced in the field, it should be stressed that, for the reasons mentioned above, they must be considered preliminary and that a conclusive statement is not warranted at the present. These studies, however, suggest that NPV could have a potential role in the treatment of COPD patients with ARF, reducing the need for endotracheal intubation and in the weaning from PPV in intubated patients. These points need to be formally confirmed by further prospective and controlled studies before recommending the generalized use of NPV in ARF as standard of care.

\section{ARF in neuromuscular disorders}

Negative pressure body ventilators were first used for patients with neuromuscular disorders in ARF during poliomyelitis epidemics in the 1930s and 1940s. Several investigators [93-95] showed that NPV reduced mortality by approximately $50 \%$ in patients with spinal polio. However, it was not as efficacious in bulbar polio because of the patient's impaired airway clearance mechanisms and the increased tendency of the upper airway to collapse during NPV use when pharyngeal muscles are paralysed. At the present time, if mechanical ventilation is indicated during acute episodes, patients with neuromuscular disorders are usually placed on positive pressure ventilation via endotracheal intubation.

The interest in noninvasive ventilation resurged during the 1980s, when the intermittent use (mostly nocturnal) of NPV was found to reverse daytime gas exchange abnormalities and symptoms of chronic hypoventilation in patients with kyphoscoliosis and neuromuscular disorders [96-101].

In the last two decades, however, only a few uncontrolled studies have been devoted to the investigation of the effect of NPV in the treatment of neuromuscular patients with ARF. LiBBy et al. [102] successfully treated 20 patients with ARF due to severe kyphoscoliosis, including one patient postpoliomyelitis, by iron lung, thus avoiding the need for endotracheal intubation. BRAUN et al. [103] studied three patients with amyotrophic lateral sclerosis and two patients with Duchenne's muscular dystrophy in ARF. NPV provided by pneumowrap successfully managed respiratory failure in one patient and permitted weaning of two other patients from invasive mechanical ventilation [103]. GARAY et al. [98] studied three patients with kyphoscoliosis, two with postpoliomyelitis, one with muscular dystrophy, and two others who presented in coma from carbon dioxide narcosis. Acute respiratory failure 
was reversed by utilizing a tank ventilator. All patients were successfully discharged and maintained at home for an average period of $10 \mathrm{yrs}$, with NPV overnight and mouthpiece positive pressure ventilation during daytime hours [98]. SHNEERSON [14] suggested that for neuromuscular disorders the chest shell or wrap style ventilator may be sufficient to overcome ARF for some patients, but for many the more effective tank ventilator may be needed. Negative pressure body ventilators can also be effective in weaning patients from intermittent positive pressure ventilation (IPPV) via endotracheal tubes [14, 92].

We have recently reported, in a retrospective study, the effects of NPV in the treatment of 15 neuromuscular patients with ARF admitted from 1980 to 1985 to our respiratory ICU [104]. They had the following diagnoses: amyotrophic lateral sclerosis (47\%), muscular dystrophy $(33 \%)$, myasthenia gravis $(13 \%)$, and multiple sclerosis (7\%). The most common causes triggering ARF in these patients were infection of upper or lower respiratory tract and heart failure. On admission, all patients exhibited severe hypoxaemia $\left(\mathrm{Pa}, \mathrm{O}_{2} 5.0 \pm 1.7 \mathrm{kPa}(37.6 \pm 12.4 \mathrm{mmHg})\right)$ and hypercapnia $\left(P \mathrm{a}, \mathrm{CO}_{2} 11.8 \pm 2.7 \mathrm{kPa}(88.2 \pm 20.4 \mathrm{mmHg})\right)$,

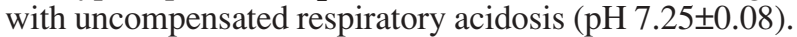
The mean Glasgow coma score (GCS) was 10.7 \pm 3.6 (range $3-15)$. Five patients $(33 \%)$ were in hypoxic-hypercapnic coma (GCS 6.4 \pm 2.1 ), and another five (33\%) were obtunded (GCS $11.8 \pm 0.4)$. All patients were managed by NPV provided by means of iron lung. Nasogastric tubes were placed for the obtunded and comatose patients to minimize the risk of bronchial aspiration. To prevent obstruction of the upper airways due to tongue retraction, an oropharyngeal airway was inserted until consciousness was regained. The treatment was successful in 12 of 15 patients $(80 \%)$. There were three treatment failures. One patient died and two required intubation. One of the intubated patients subsequently died whilst using invasive ventilatory support. The effects of NPV on arterial blood gases and $\mathrm{pH}$ in the 12 patients treated successfully are shown in figures 7 and 8 [104].

Although these reports suggest that NPV provided by iron lung can be effective in the treatment of ARF in patients with neuromuscular diseases, many important questions remain unanswered. Prospective controlled studies are needed to confirm the results of uncontrolled reports [98, 102-104] and to clarify the impact of noninvasive ventilatory support techniques both on mortality and length of hospital stay, for patients with neuromuscular disorders who develop ARF. The limitations of NPV must also be considered. Lack of protection of the airway and risk of intermittent collapse with resulting obstructive apnoeas are potential drawbacks to using NPV in patients with neuromuscular diseases [40, 41].

\section{Other applications}

The use of CNEP in adult respiratory distress syndrome and in persistent flail chest deformity has been described in some case reports. SANYAL et al. [105] successfully used CNEP administered by a tank respirator in the management of progressive respiratory insufficiency in an adult with bilateral alveolar disease. The application of CNEP produced a substantial and sustained increase in $\mathrm{Pa}_{\mathrm{a}} \mathrm{O}_{2}$, permitting inspired oxygen concentration to be reduced to $40 \%$ within $24 \mathrm{~h}$. Concomitant

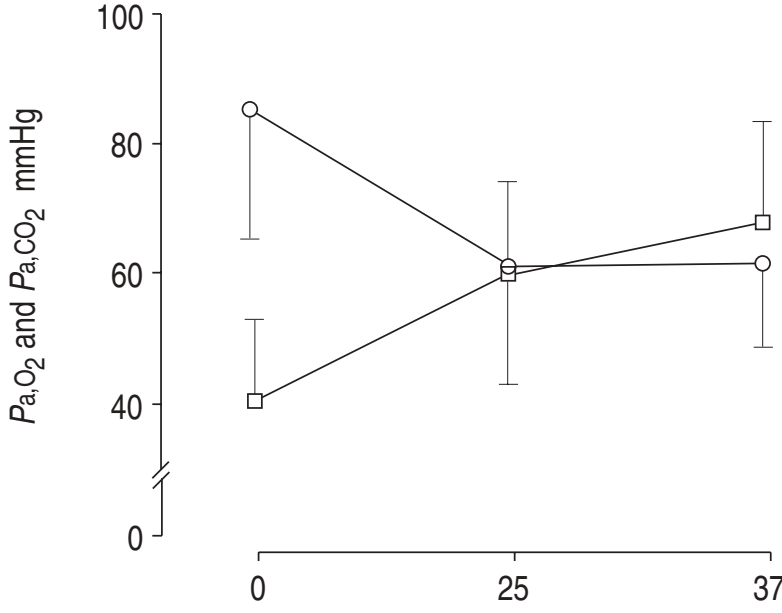

Ventilatory treatment $\mathrm{h}$

Fig. 7. - Effects of negative pressure ventilation in $\mathrm{Pa}_{\mathrm{a}} \mathrm{O}_{2}(-\square-(-)$ and $\mathrm{Pa}_{\mathrm{a}, \mathrm{CO}_{2}}(-\mathrm{O}-$ ) in 12 patients with neuromuscular disorders and acute respiratory failure. $P \mathrm{a}, \mathrm{O}_{2}:$ arterial oxygen tension; $\mathrm{Pa}_{\mathrm{a}, \mathrm{CO}_{2}}$ : arterial carbon dioxide tension; $1 \mathrm{mmHg}=0.133 \mathrm{kPa}$.

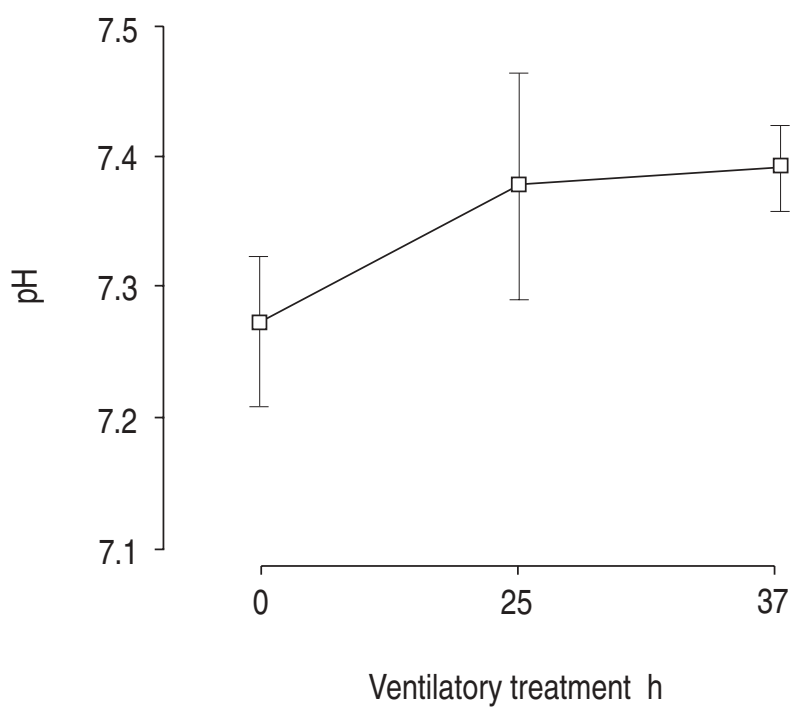

Fig. 8. - Effects of negative pressure ventilation on $\mathrm{pH}$ in 12 patients with neuromuscular disorders and acute respiratory failure.

decreases in intrapulmonary right-to-left shunt and respiratory frequency were also ascertained. No adverse effects on blood pressure or heart rate was reported during CNEP [105]. MoRRIS and ElLIOTT [106] reported the use of CNEP to successfully treat adult respiratory distress syndrome in a 19 year old woman who resisted the application of positive airway pressure. The patient was agitated and unwilling to maintain a tight face mask for the administration of CPAP. After careful discussion with the patient, it was decided to administer CNEP and to avoid endotracheal intubation. Arterial hypoxaemia was reversed with $-26 \mathrm{cmH}_{2} \mathrm{O}$ of extrathoracic pressure, produced by a modified Emerson iron lung. Cerebral and renal functions were maintained, and barotrauma did not occur. The patient required CNEP for 9 days and was discharged after 12 days [106]. HARTKE and BLOCK [107] successfully employed a chest shell to deliver CNEP in order to stabilize persistent flail chest deformities in a 
67 year old man, following total sternectomy and requiring long-term mechanical respiratory assistance. The application of CNEP was well-tolerated and permitted the patient to be disconnected from mechanical ventilation, resuming spontaneous breathing with continuous oxygen saturation stable at $98 \%$ in ambient air [107].

SAWIKA et al. [108] treated the cardiorespiratory complications developed during pregnancy in four of six patients with kyphoscoliosis using a tank ventilator. The tank was used in one case as a first-line of treatment to overcome an acute episode of respiratory failure, allowing the pregnancy to continue until a live infant could be delivered, and in the others to achieve a successful return to spontaneous breathing after conventional positive pressure ventilation. The use of the tank respirator was not detrimental to foetal development and did not cause maternal discomfort, or prevent infant-mother bonding or breast-feeding after delivery. SAwIKA et al. [108] claimed that NPV provides effective relief both for respiratory and cardiac failure, and is suitable for short-term or long-term use during pregnancy or after delivery.

Recently AmBRosino and co-workers [109] reported the successful treatment with CNEP applied by ponchowrap ventilator in a heart-lung transplanted patient with ARF induced by Staphylococcus aureus pneumonia. Continuous negative pressure, applied because of an intolerance to CPAP, resulted in a significant improvement in $\mathrm{Pa}_{\mathrm{a}} \mathrm{O}_{2}$, allowing a progressive reduction of $F_{\mathrm{I}, \mathrm{O}_{2}}$. Mechanical ventilation and oxygen therapy were discontinued 8 days after the beginning of the acute episode [109].

\section{Advantages, contradindications and clinical side-effects of NPV}

The major advantages of NPV (table 3 ) are avoidance of endotracheal intubation and its attendant complications, and preservation of physiological functions, such as speech, cough, swallowing and feeding. Furthermore, NPV, unlike noninvasive PPV, allows fibrebronchoscopy to be performed for therapeutic and diagnostic procedures without disconnection from the ventilator [44]. However, the limitations of this therapeutic modality must be seriously kept in mind: 1) the lack of protection of the upper airway, especially in unconscious patients or in those with neurological disorders associated to bulbar dysfunction, which may induce pulmonary aspiration of material from the pharynx; and 2) upper airway obstruction due to collapse of the tongue on the posterior pharyngeal wall or to the lack of preinspiratory upper airway muscle activation, which may occur in unconscious patients, or in those with bulbar dysfunction, or in patients with sleep apnoea syndrome during sleep. In unconscious patients with normal bulbar function, however, the placement of a nasogastric tube and the positioning of an oropharyngeal airway can minimize the risk of aspiration pneumonia and upper airway obstruction due to the collapse of the tongue, respectively. In the other circumstances, endotracheal intubation must be performed and the possibility of switching to standard mechanical ventilation must be considered. The major contraindications of NPV are reported in table 3.

At the present time, data on clinical side-effects during NPV have been mainly obtained in patients chronically ventilated at home. In these studies, the most common side-effects reported were poor compliance, upper airway obstruction and musculoskeletal pain (table 4); whereas, in patients with ARF the most frequent side-effect reported were poor compliance [26] and upper airway obstruction [44].

All noninvasive ventilatory techniques, reducing the need for endotracheal intubation and avoiding its attendant complications and difficulty in weaning, should be considered potentially advantageous in comparison with

Table 3. - Advantages and contraindications of negative pressure ventilation (NPV)

\begin{tabular}{ll}
\hline Advantages & Contraindications \\
\hline - No need for endotracheal intubation & - Gastrointestinal bleeding \\
- Intermittent delivery of ventilation & - Rib fractures \\
- Airway suction without disconnection from ventilator & - Recent abdominal surgery \\
- Physiological cough & - Unco-operative patients \\
- Diagnostic and therapeutic procedures by fibrebronchoscopy & - Sleep apnoea syndrome \\
- Nuring ventilation & \\
\hline
\end{tabular}

Table 4. - Clinical side-effects of negative pressure ventilation (NPV)

\begin{tabular}{|c|c|c|c|c|c|}
\hline Side-effect & Type of device & $\begin{array}{l}\text { Home long-term } \\
\text { application* }\end{array}$ & $\begin{array}{l}\text { Application in } \\
\text { critical care setting* }\end{array}$ & $\begin{array}{l}\text { First } \\
\text { author }\end{array}$ & [Ref] \\
\hline Tiredness and/or depression & PW & 4/92 & - & SHAPIRO & [110] \\
\hline \multirow{2}{*}{$\begin{array}{l}\text { Musculoskeletal pain or } \\
\text { tightness }\end{array}$} & PW & $5 / 92$ & - & SHAPIRO & [110] \\
\hline & PW & $7 / 20$ & - & ZIBRAK & [111] \\
\hline Oesophagitis & PW & $2 / 20$ & - & ZIBRAK & [111] \\
\hline Rib fractures and pneumothorax & PW & $1 / 20$ & - & ZIBRAK & [111] \\
\hline Impaired sleep quality & PW & $2 / 20$ & - & ZIBRAK & [111] \\
\hline \multirow[t]{3}{*}{ Upper airway obstruction } & IL & - & $2 / 10$ & Todisco & [44] \\
\hline & PW & $11 / 12^{\S}$ & - & HILL & [40] \\
\hline & PW,C,IL & $3 / 37^{\circ} \S$ & - & $\mathrm{BACH}$ & [41] \\
\hline \multirow[t]{2}{*}{ Poor compliance } & PW & - & $6 / 20$ & MontSERRAT & [26] \\
\hline & PW & $34 / 92$ & - & SHAPIRO & [110] \\
\hline
\end{tabular}

PW: pneumowrap; IL: iron lung; C: cuirass. *: number of side-effects/total patients studied; ${ }^{\circ}$ : patients in whom the diagnosis was supported by polysomnographic data; §: uncontrolled study. 
standard mechanical ventilation from an economic point of view. The difficulty in weaning is a crucial problem, strictly related to a long hospital stay and consequently to a high expenditure. Patients receiving prolonged mechanical ventilation (for more than 7 days) have been found to consume a particularly high fraction of economic ICU resources $[112,113]$. However it is very important to stress that all the theoretical economic advantages of noninvasive ventilatory techniques must be rigorously documented in terms of: feasibility in weaning; incidence of complications; hospital stay; length of nursing assistance. Noninvasive techniques of assisted ventilation require considerable medical and nursing expertise and, for this reason, it would be very useful to have an accurate economic analysis of training programme costs, in order to acquire a high degree of expertise in dealing with noninvasive ventilatory techniques.

In conclusion, although the use of NPV has been found to be efficacious in the treatment of chronic respiratory failure of patients with neuromuscular and chest wall disorders [15], it remains a matter of debate for patients with ARF due to neuromuscular disorders and exacerbation of COPD. In fact, of all the studies concerning the application of NPV during ARF in these patients have not been prospective and randomly controlled; even though these reports suggest a possible therapeutic role for NPV in the treatment of ARF, they must be formally confirmed by controlled studies comparing NPV versus conventional mechanical ventilation. Apart from this comparison, however, it is important to stress the potential practical advantages in instituting NPV at an early phase of ARF in order to prevent the need for endotracheal intubation and its attendant complications. The limitations of NPV and, in particular, the induction of upper airway obstruction must always be kept in mind; when this side-effect occurs, it must be promptly corrected by placing a pharyngeal airway, or by using another ventilatory technique (noninvasive positive pressure ventilation or endotracheal intubation). The possibility of combining NPV with noninvasive positive pressure ventilation (CPAP) has been reported to be successful in overcoming upper airways obstruction following extubation in infants weaned from IPPV by means of NPV [68]. This option provides an idea of how these two noninvasive techniques may interact, thus increasing the armamentarium of noninvasive ventilatory techniques in managing ARF

During the last few years, negative pressure ventilation has regained popularity in the paediatric field as a first-line of treatment in acute respiratory failure, as a weaning technique from positive pressure ventilation and as efficacious substitute for positive end-expiratory pressure when used in continuous mode (continuous negative extrathoracic pressure). Furthermore, continuous negative extrathoracic pressure associated with intermittent mandatory ventilation has been used as initial therapy for infants who meet extracorporeal membrane oxygenation criteria, without increased morbidity or mortality related to delayed referral to extracorporeal membrane oxygenation [71]. This application of continuous negative extrathoracic pressure must be considered at the present time to be experimental as further research is needed in order to recommend it as a standard of care.

\section{References}

1. Stauffer JL, Olson DE, Petty TL. Complications and consequences of endotracheal intubation and tracheotomy. Am J Med 1981; 70: 65-76.

2. Pingleton SK. Complication of acute respiratory failure. Am Rev Respir Dis 1988; 137: 1463-1493.

3. Tobin MJ. Mechanical ventilation. N Engl J Med 1994; 330: 1056-1061.

4. Dalziel J. On sleep and an apparatus for promoting artificial respiration. Br Assoc Advancement Sci 1838; 2: 127-134.

5. Woillez EJ. Du spirophore, appareil de sauvetage pour le traitment de l'asphyxie, et principalement de l'asphyxie des noyes et de nouveaunés. Bull Acad Méd (Paris) 1876; 2 (5): 611-619.

6. Emerson JH. In: The evolution of iron lungs. Cambridge, MA, J.H. Emerson Co., 1978.

7. Hill NS. Clinical applications of body ventilators. Chest 1986; 90: 897-905.

8. Doe OW. Apparatus for resuscitating asphyxiated children. Boston Med Surg J 1889; 120: 9-17.

9. Woolam CHM. The development of apparatus for intermittent negative pressure respiration (1) 1832-1918. Anaesthesia 1976; 31: 537-547.

10. Chillingworth FP, Hopkins R. Physiologic changes produced by variations in lung distention. J Lab Clin Med 1919; 4: 555-560.

11. Drinker P, Shaw LA. An apparatus for the prolonged administration of artificial respiration. I. A design for adults and children. J Clin Invest 1929; 7: 229-247.

12. Drinker PA, McKhann CF. The iron lung: first practical means of respiratory support. JAMA 1986; 255 : 1476-1480.

13. Lassen HCA. A preliminary report on the 1952 epidemic of poliomyelitis in Copenhagen with special reference to the treatment of acute respiratory insufficiency. Lancet 1953; i: $37-41$.

14. Shneerson JH. Noninvasive and domiciliary ventilation: negative pressure techniques. Thorax 1991; 46: 131-135.

15. Levine S, Henson D. Negative pressure ventilation. In: Tobin MJ, ed. Principles and Practice of Mechanical Ventilation. New York, McGraw-Hill, 1994; pp. 393-411.

16. Shepard FM. A negative-pressure tank-type respirator for the neonate. Anesth Analg 1970; 49: 413-419.

17. Aaron J, McCool FD, Benditt J, Hill NS. Evaluation of trigger sensitivity of patient-triggered negative pressure ventilators. Am J Respir Crit Care Med 1995; 151: A237.

18. Kinnear W, Petch M, Taylor G, Shneerson J. Assisted ventilation using cuirass respirators. Eur Respir J 1988; 1: 198-203.

19. Cormier Y, Lecours R, Legris C. Mechanisms of hyperinflation in asthma. Eur Respir J 1990; 3: 619-624.

20 Fabbri M, Fasano L, Sturani C, Meotti A, Bassein L, Gunella G. Effetti ventilatori acuti del polmone d'acciaio e del "poncho" in pazienti affetti da broncopneumopatia cronica ostruttiva. Rass Pat App Respir 1992; 7: 345-350.

21. Easa D, Mundie TG, Finn KC, Hashiro G, Balaraman V. Continuous negative extrathoracic pressure versus positive end-expiratory pressure in piglets after saline lung lavage. Pediatr Pulmonol 1994; 17: 161-168.

22. Whittenberger JL, Ferris BG Jr. Alterations of respiratory function in poliomyelitis. Am J Phys Med 1952; 31: 226-237.

23. Cooper CB, Harris ND, Howard P. Acute effects of external negative pressure ventilation in chronic obstructive 
pulmonary disease compared with normal subjects. Eur Respir J 1991; 4: 63-68.

24. Smith IE, King MA, Shneerson JM. Choosing a negative pressure ventilation pump: are there any important differences? Eur Respir J 1995; 8: 1792-1795.

25. Corrado A, Bruscoli G, De Paola E, Ciardi-Duprè GF, Baccini A, Taddei M. Respiratory muscle insufficiency in acute respiratory failure of subjects with severe COPD treatment with intermittent negative pressure ventilation. Eur Respir J 1990; 3: 644-648.

26. Montserrat JM, Martos JA, Alarcon A, Celis R, Plaza V, Picado C. Effect of negative pressure ventilation on arterial blood gas pressure and inspiratory muscle strength during an exacerbation of chronic obstructive lung disease. Thorax 1991; 46: 6-8.

27. Rochester DF, Braun NMT, Laine S. Diaphragmatic energy expenditure in chronic respiratory failure. $\mathrm{Am} \mathrm{J}$ Med 1977; 63: 223-232.

28. Goldstein RS, Molotiu N, Skrastins R, Long S, Contreras M. Assisting ventilation in respiratory failure by negative pressure ventilation and by rocking bed. Chest 1987; 92: 471-474.

29. Nava S, Ambrosino N, Zocchi L, Rampulla C. Diaphragmatic rest during negative pressure ventilation by pneumowrap. Chest 1990; 98: 857-865.

30. Fernandez E, Weiner P, Meltzer E, Lutz MM, Badish DB, Cherniack RM. Sustained improvement in gas exchange after negative pressure ventilation for 8 hours per day on 2 successive days in chronic airflow limitation. Am Rev Respir Dis 1991; 144: 390-394.

31. Rodenstein DO, Cuttitta G, Stanescu DC. Ventilatory and diaphragmatic EMG changes during negative pressure ventilation in healthy subjects. J Appl Physiol 1988; 64: 2272-2278.

32. Rodenstein DO, Stanescu DC, Cuttita G, Liistro G, Veriter C. Ventilatory and diaphragmatic EMG responses to negative pressure ventilation in airflow obstruction. $J$ Appl Physiol 1988; 65: 1621-1626.

33. Gigliotti F, Duranti R, Fabiani A, Schiavina M, Scano G. Suppression of ventilatory muscle activity in healthy subjects and COPD patients with negative pressure ventilation. Chest 1991; 99: 1186-1192.

34. Gigliotti F, Spinelli A, Duranti R, Gorini M, Goti P, Scano G. Four week negative pressure ventilation improves respiratory function in severe hypercapnic COPD patients. Chest 1994; 105: 87-94.

35. Cropp A, Di Marco AF. Effects of intermittent negative pressure ventilation on respiratory muscle function in patients with severe chronic obstructive pulmonary disease. Am Rev Respir Dis 1987; 135: 1056-1061.

36. Gutierrez M, Beroiza T, Contreras G, et al. Weekly cuirass ventilation improves blood gases and inspiratory muscle strength in patients with chronic airflow limitation and hypercapnia. Am Rev Respir Dis 1988; 138: 617-623.

37. Scano G, Gigliotti F, Duranti R, Spinelli A, Gorini M, Schiavina M. Changes in ventilatory muscle function with negative pressure ventilation in patients with severe COPD. Chest 1990; 97: 322-327.

38. Levy RD, Bradley TD, Newman SL, Macklem PT, Martin JC. Negative pressure ventilation: effects on ventilation during sleep in normal subjects. Chest 1989; 95: 95-99.

39. Levy RD, Cosio MG, Gibbons L, Macklem PT, Martin JC. Induction of sleep apnoea with negative pressure ventilation in patients with chronic obstructive lung disease. Thorax 1992; 47: 612-615.

40. Hill NS, Redline S, Carskadon MA, Curran FJ, Millman
RP. Sleep-disordered breathing in patients with Duchenne muscular dystrophy using negative pressure ventilators. Chest 1992; 102: 1656-1662.

41. Bach JR, Penek J. Obstructive sleep apnea complicating negative pressure ventilatory support in patients with chronic paralytic/restrictive ventilatory dysfunction. Chest 1991; 99: 1386-1393.

42. Schiavina M, Fabbri A. Intermittent negative pressure ventilation in patients with respiratory failure. Monaldi Arch Chest Dis 1993; 48: 169-175.

43. Sanna A, Veriter C, Stanescu D. Upper airway obstruction induced by negative-pressure ventilation in awake healthy subjects. J Appl Physiol 1993; 75: 546-552.

44. Todisco T, Eslami A, Scarcella L, Baglioni S, Scavizzi F, Dottorini M. Flexible bronchoscopy during iron lung mechanical ventilation in nonintubated patients. $J$ Bronch 1995; 2: 200-205.

45. Marino WD, Jain NK, Pitchumoni CS. Induction of lower esopheageal sphincter (LES) dysfunction during use of the negative pressure body ventilator. Am J Gastroenterol 1988; 83: 1376-1380.

46. Marino WD, Pitchumoni CS. Reversal of negative pressure ventilation-induced lower esophageal sphincter dysfunction with metoclopramide. Am J Gastroenterol 1992; 87: 190-194.

47. Krumpe PE, Zidulka A, Urbanetti J, Anthonisen NR. Comparison of the effects of continuous negative external chest pressure and positive end-expiratory pressure on cardiac index in dogs. Am Rev Respir Dis 1977; 115: 39-45.

48. Maloney JV, Whittenberger JL. Clinical implication of pressures used in the body respirator. Am J Med Sci 1951; 221: 425-430.

49. Skabursis M, Helal R, Zidulka A. Hemodynamic effects of external continuous negative pressure ventilation compared with those of continuous positive pressure ventilation in dogs with acute lung injury. Am Rev Respir Dis 1987; 136: 886-891.

50. Lockhat D, Langleben D, Zidulka A. Hemodynamic differences between continuous positive and two types of negative pressure ventilation. Am Rev Respir Dis 1992; 146: 677-680.

51. Ambrosino N, Cobelli F, Torbicki A et al. Hemodynamic effects of negative pressure ventilation in patients with COPD. Chest 1990; 97: 850-856.

52. Delivoira-Papadopulos M, Levison H, Swyer PR. Intermittent positive pressure respiration as a treatment in severe respiratory distress syndrome. Arch Dis Child 1965; 40: 474-479.

53. Monin P, Cashore WJ, Hakanson DO, Cowett RM, Oh W. Assisted ventilation in the neonate-comparison between positive and negative respirators. Pediatr Res 1976; 10: 464.

54. Tyler DC. Positive end-expiratory pressure: a review. Crit Care Med 1983; 11: 300-308.

55. Brancalari E, Stocker JT, eds. In: Bronchopulmonary Dysplasia. Washington DC, Hemisphere, 1988; pp. 20-45.

56. Brancalari E, Gerhardt T, Monkus E. Simple device for producing continuous negative pressure in infants with IRDS. Pediatrics 1973; 52: 128-130.

57. Alexander G, Gerhardt T, Brancalari E. Hyaline membrane disease: comparison of continuous negative pressure and nasal positive airway pressure in its treatment. Am J Dis Chest 1979; 133: 1156-1159.

58. Outerbridge EW, Roloff DW, Stern L. Continuous negative pressure in the management of severe respiratory distress syndrome. J Pediatr 1972; 81: 384-391.

59. Fanaroff AA, Cha CC, Sosa R, Crumrine RS, Klaus MH. 
Controlled trial of continuous negative external pressure in the treatment of severe respiratory distress syndrome. J Pediatr 1973; 82: 921-928.

60. Silverman WA, Sinclair JC, Gandy GM, Finster M, Baumann WA, Agate FJ. A controlled trial of management of respiratory distress syndrome in a body-enclosing respirator. I. Evaluation of safety. Pediatrics 1967; 39: 740-748.

61. Vert P, Monin P, Sibout M. Intracranial venous pressure in newborns: variations in physiologic state and in neurologic and respiratory disorders. In: Stern I, FriisHansen B, Kildberg P, eds. Intensive Care in the Newborn. Lancaster, England, MTP Press, 1979; pp. 185-186.

62. Samuels MP, Southall DP. Negative extrathoracic pressure in the treatment of respiratory failure in infants and young children. BMJ 1989; 299: 1253-1257.

63. Sillis JH, Cvetnic WG, Pietz J. Continuous negative pressure in the treatment of infants with pulmonary hypertension and respiratory failure. J Perinat 1989; 9: 43-48.

64. Cvetnic WG, Waffarn F, Martin JM. Continuous negative pressure and intermittent mandatory ventilation in the management of pulmonary interstitial emphysema: a preliminary study. J Perinat 1989; 9: 26-32.

65. Palmer K, Spencer SA, Wickramasinghe Y, Wright T, Samuels M, Rolfe P. Negative extrathoracic pressure ventilation: evaluation of the neck seal. Early Hum Dev 1994; 37: 67-72.

66. Langer JC, Filler RM, Coles J, Edmonds JF. Plication of the diaphragm for infants and young children with phrenic nerve palsy. J Pediatr Surg 1988; 23: 749-751.

67. Raine J, Samuels MP, Mok Q, Shinebourne EA, Southall DP. Negative extrathoracic pressure ventilation for phrenic nerve palsy after pediatric cardiac surgery. Br Heart $J$ 1992; 67: 308-311.

68. Hartmann H, Jawad MH, Noyes J, Samuels MP, Southall DP. Negative extrathoracic pressure ventilation in central hypoventilation syndrome. Arch Dis Child 1994; 70: 418-423.

69. Sell LL, Cullen ML, Whittlessey GC, et al. Hemorrhagic complications during extracorporeal membrane oxygenation: prevention and treatment. J Pediatr Surg 1986; 21: 1087-1091.

70. Nading JH. Historical controls for extracorporeal membrane oxygenation in neonates. Crit Care Med 1989; 17 (5): 423-425.

71. Cvetnic WG, Shouptaugh M, Sills JH. Intermittent mandatory ventilation with continuous negative pressure compared with positive end-expiratory pressure for neonatal hypoxemia. J Perinat 1992; 12: 316-324.

72. Boutourline-Young HJ, Whittenberger JL. The use of artificial respiration in pulmonary emphysema accompanied by high carbon dioxide levels. J Clin Invest 1951; 30: 838-844.

73. Stone DJ, Schwartz R, Neuman W, Feltman JA, Lovelock FJ. Precipitation by pulmonary infection of acute anoxia, cardiac failure and respiratory acidosis in chronic pulmonary disease. Am J Med 1953; 14: 14-21.

74. Lovejoy FW, Yu PNG, Nye RE, Joos HA, Simpson JH. Pulmonary hypertension. III. Physiologic studies in three cases of carbon dioxide narcosis treated by artificial respiration. Am J Med 1954; 16: 4-11.

75. Marks A, Bocles J, Morganti L. A new ventilatory assister for patients with respiratory acidosis. $N$ Engl J Med 1963; 268: 61-67.

76. Gunella G, Petrella A, Melica A. Terapia del coma respiratorio secondario ad enfisema polmonare cronico. Min Pneumol 1966; 19: 254-261.
77. Sala L. L'uso del polmone d'acciaio nell'insufficienza respiratoria: indicazioni e limiti. In: Spina G, Bonsignore G, eds. La Patologia Respiratoria Fisiopatologia. Clinica Terapia. Vol. 3. Torino, Ediz. Medico Scientifiche, 1978; pp. 393-410.

78. Petty TL, Lakshminarayan S, Sahn SA, Zwillich CW, Nett LM. Intensive respiratory care unit. JAMA 1975; 233: 34-37.

79. Curtis RJ, Hudson LD. Emergent assessment and management of acute respiratory failure in COPD. Clin Chest Med 1994; 15: 481-500.

80. Rossi A, Pingleton SK. Respiratory intensive care: a new challenge in the third millennium. Monaldi Arch Chest Dis 1993; 48: 113-117.

81. Knaus WA. Prognosis with mechanical ventilation: the influence of disease, severity of disease, age, and chronic health status on survival from an acute illness. Am Rev Respir Dis 1989; 140: S8-S13.

82. Langer M, Mosconi P, Cigada M, Mandelli M, and the intensive care unit group of infection control. Long-term respiratory support and risk of pneumonia in critically ill patients. Am Rev Respir Dis 1989; 140: 302-305.

83. Wessel-Aas T, Vale JR, Hauge HE. Artificial ventilation in chronic pulmonary insufficiency: indication and prognosis. Scand J Respir Dis 1970; (Suppl. 72): 36-41.

84. Gunella G. Traitement de l'insuffisance respiratoire aigué des pulmonaires chroniques avec le poumon d'acier: résultat dans une série de 560 cas. Ann Méd Physique 1980; 2: $317-327$

85. Corrado A, Bruscoli G, Messori A, et al. Iron lung treatment of subjects with COPD in acute respiratory failure: evaluation of short and long-term prognosis. Chest 1992; 101: 692-696.

86. Sauret JM, Guitart AC, Frojan GR, Cornudella R. Intermittent short-term negative pressure ventilation and increased oxygenation in COPD patients with severe hypercapnic respiratory failure. Chest 1991; 100: 455459.

87. Corrado A, Gorini M, De Paola E, et al. Iron lung treatment of acute on chronic respiratory failure: $16 \mathrm{yrs}$ of experience. Monaldi Arch Chest Dis 1994; 49: 552-555.

88. Weitzenblum E. Acute respiratory failure in the patients with obstructive airways disease. In: Fishman AP, ed. Pulmonary Diseases and Disorders. 2nd edn. New York, McGraw-Hill, 1988; pp. 2287-2298.

89. Bozza-Marrubini M. Classification of coma. Intensive Care Med 1984; 10: 217-220.

90. Menzies R, Gibbons W, Goldberg P. Determinants of weaning and survival among patients with COPD who require mechanical ventilation for acute respiratory failure. Chest 1989; 95: 398-405.

91. Corrado A, De Paola E, Messori A, Bruscoli G, Nutini S. The effect of intermittent negative pressure ventilation and long-term oxygen therapy for patients with COPD: a 4 year study. Chest 1994; 105: 95-99.

92. Del Bufalo C, Fasano L, Quarta CC, Nastasi M, Gunella G. Use of extrathoracic negative pressure ventilation in weaning COPD and kyphoscoliotic patients from mechanical ventilation. Respir Care 1994; 39: 21-29.

93. Wilson JL. Acute anterior poliomyelitis. N Engl J Med 1932; 206: 887-893.

94. Crone NL. The treatment of acute poliomyelitis with the respirator. N Engl J Med 1934; 210: 621-623.

95. Brahdy MB, Lenarsky M. Respiratory failure in acute epidemic poliomyelitis. J Pediat 1936; 8: 420-433.

96. Weirs PW, Le Coultre R, Dallinga OT, van Dijl W, Meinesz AF, Sluiter HG. Cuirass respirator treatment 
of chronic respiratory failure in scoliotic patients. Thorax 1977; 32: 221-228.

97. Splaingard ML, Frates RC Jr, Jefferson LS, Rosen CL, Harrison GM. Home negative pressure ventilation: report of 20 years of experience in patients with neuromuscular disease. Arch Phys Med Rehabil 1985; 66: 239-242.

98. Garay SM, Turino GM, Goldring RM. Sustained reversal of chronic hypercapnia in patients with alveolar hypoventilation syndromes: long-term maintenance with noninvasive nocturnal mechanical ventilation. Am J Med 1981; 70: 269-274.

99. Curran FJ. Night ventilation by body respirators for patients in chronic respiratory failure due to late-stage Duchenne muscular dystrophy. Arch Phys Med Rehabil 1981; 63: 270-274.

100. Goldstein RS, Molotiu N, Skrastins R, et al. Reversal of sleep-induced hypoventilation and chronic respiratory failure by nocturnal negative pressure ventilation in patients with restrictive ventilatory impairment. Am Rev Respir Dis 1987; 135: 1049-1055.

101. Mohr CH, Hill NS. Long-term follow-up of nocturnal ventilatory assistance in patients with respiratory failure due to Duchenne-type muscular dystrophy. Chest 1990; 97: 91-96.

102. Libby BM, Briscoe WA, Boyce B, Smith JP. Acute respiratory failure in scoliosis or kyphosis. Am J Med 1982; 73: $532-538$.

103. Braun SR, Sufit RL, Giovannoni R, O'Connor M, Peters H. Intermittent negative pressure ventilation in the treatment of respiratory failure in progressive neuromuscular disease. Neurology 1987; 37: 1874-1875.

104. Corrado A, Gorini M, De Paola E. Alternative techniques for managing acute neuromuscular respiratory failure. Sem Neurol 1995, 15: 84-89.

105. Sanyal SK, Bernal R, Hughes WT, Feldman S. Continuous negative chest wall pressure: successful use for severe respiratory distress in an adult. JAMA 1976; 236: 1727-1728.

106. Morris AH, Elliott GC. Adult respiratory distress syndrome: successful support with continuous negative extrathoracic pressure. Crit Care Med 1985; 13: 989-990.

107. Hartke RH, Block AJ. External stabilization of flail chest using continuous negative extrathoracic pressure. Chest 1992; 102: 1283-1285.

108. Sawika EH, Spencer GT, Branthwaite MA. Management of respiratory failure complicating pregnancy in severe kyphoscoliosis: a new use for an old technique? $\mathrm{Br} \mathrm{J}$ Dis Chest 1986; 80: 191-196.

109. Ambrosino N, Rubini F, Callegari G, Nava S, Fracchia C. Noninvasive mechanical ventilation in the treatment of acute respiratory failure due to infectious complications of lung transplantation. Monaldi Arch Chest Dis 1994; 49: 311-314.

110. Shapiro SH, Ernst P, Gray-Donald K, et al. Effect of negative pressure ventilation in severe chronic obstructive pulmonary disease. Lancet 1992; 340: 1425-1429.

111. Zibrak JD, Hill NS, Federman EC, Kwa SL, O'Donnel C. Evaluation of intermittent long-term negative-pressure ventilation in patient with severe chronic obstructive pulmonary disease. Am Rev Respir Dis 1988; 138: $1515-1518$.

112. Osborne ML. Physicians decisions regarding life support in the intensive care unit. Chest 1992; 101: 217-224.

113. Wagner DP. Economics of prolonged mechanical ventilation. Am Rev Respir Dis 1989; 140: 514-518. 